IFN Working Paper No. 867, 2011

\title{
Acquisitions, Entry, and Innovation in Oligopolistic Network Industries
}

Pehr-Johan Norbäck, Lars Persson and Joacim Tåg 


\title{
Acquisitions, Entry, and Innovation in Oligopolistic Network Industries*
}

\author{
Pehr-Johan Norbäck \\ Research Institute of Industrial Economics (IFN) \\ Lars Persson \\ Research Institute of Industrial Economics (IFN) and CEPR \\ Joacim Tåg \\ Research Institute of Industrial Economics (IFN)
}

June 25, 2014

\begin{abstract}
In industries with network effects, incumbents' installed bases create barriers to entry that discourage entrepreneurs from developing new innovations. Yet, entry is not the only commercialization route for entrepreneurs. We show that the option of selling to an incumbent increases the innovation incentives for entrepreneurs when the network effects are strong and incumbents compete to preemptively acquire innovations. Thus, we establish that network effects and installed bases do not necessarily restrict the innovation incentives, and that network effects promote acquisitions over entry.

Keywords: Acquisitions; entry; network effects; innovation; R\&D.

JEL classification: L10; L15; L26; L50; O31.
\end{abstract}

\footnotetext{
${ }^{*}$ We gratefully acknowledge financial support from the NET Institute (http://www.netinst.org), the Kauffman Foundation, the Marianne and Marcus Wallenberg Foundation and Tom Hedelius' and Jan Wallander's Research Foundation. This paper was written within the Gustaf Douglas Research Program on Entrepreneurship. We thank James Anton, Richard Gilbert, Michael Katz, Dina Nieman, Vasiliki Skreta, Lukas Wiewiorra, Juuso Välimäki, seminar participants at the FDPE IO Workshop at HECER (Helsinki), the NET Institute Conference at NYU/Stern (New York), the 8th ZEW Conference: The Economics of ICT (Mannheim) and the ParisTech Telecom Economics Seminar Series (Paris) for excellent comments and suggestions. An earlier version of this paper was distributed with the title "Entrepreneurial Innovations in Network Industries".
} 


\section{Introduction}

In industries with network effects, incompatibility with incumbents' installed bases creates barriers to entry (Farrell and Klemperer (2007)). These entry barriers can discourage entrepreneurs from developing new innovations; particularly when the network effects are strong. Yet, entry is not the only commercialization route for entrepreneurs. Selling to established firms can prove to be extremely lucrative, in particular if the entrepreneur has managed to gather a sufficient initial user base. The business press contains numerous accounts of preemptive bidding between incumbents for young firms. One example is Apple's acquisition of the music site Lala.com. BusinessWeek (2010) described the acquisition as follows: "Late last year, Apple entered the bidding for the online music site Lala.com, after Google and several other potential acquirers had gotten involved. The company moved unusually quickly, closing the deal in a few weeks, rather than the more typical two to three months. It was clear that Apple didn't want to lose out again, and especially not to Google". Another example is the battle between Google and Facebook over Skype in 2011. A Reuters article notes: "Indeed, some speculate that Google could be bidding for Skype just to keep it out of the hands of other companies. Any deal that takes a great asset away from Facebook is a win for Google". ${ }^{1}$ Finally, Google's acquisition of Waze in 2013 for over $\$ 1$ billion is a good example of the mechanism we describe in this paper. Waze made a traffic navigation application for smart phones that updated itself based on users' input, for example, on traffic conditions. This made the installed base of the startup valuable as more users resulted in more accurate information. As noted by The Economist (Economist (2013)): "Apple was rumored to have been interested. And before Google swiped it, Facebook, which lacks maps of its own, was said to be close to a deal. [...] In maps Google is already far ahead of both its rivals. [...] Google may therefore have calculated that it is worth paying $\$ 1$ billion just to deny Facebook and Apple a chance of making up a little ground".

In this paper, we study how innovation incentives in industries with installed bases and network effects are affected by bidding competition between incumbents for new entrepreneurial firms. This is done by introducing an endogenous acquisition auction into a canonical model of competition in an industry with network effects. We show how the option of selling to an incumbent increases the innovation incentives for entrepreneurs, in particular when network effects are strong and entry is hindered by incumbent installed bases. We establish that network effects and installed bases need not restrict the

\footnotetext{
${ }^{1}$ Source:

http://www.reuters.com/article/2011/05/06/us-facebook-google-skypeidUSTRE74505A20110506 Accessed April 2013.
} 
innovation incentives for entrepreneurial firms, and that selling to an incumbent can lead to a higher consumer surplus than what entry into the market would have generated.

The model looks as follows. In Stage 1, an entrepreneur exerts effort to discover an innovation. If the effort is successful, the entrepreneur attracts an initial user base which is smaller than the installed base of incumbents (locked-in consumers). In Stage 2 , the entrepreneur decides on the commercialization route by arranging a first price auction for the innovation and the initial user base. The bidders are incumbent firms with established installed bases of locked-in users. The reservation price is the value of entry into the market, so that the entrepreneur enters the market if no incumbent submits a high enough bid. Product market competition for new consumers takes place in Stage 3. New consumers first form expectations of network size for each firm. Network size consists of locked-in consumers and the expected number of new consumers. They then decide which firm to buy from, given their expectations. Finally, firms compete in quantities, taking the expectations as given.

The model shows how the option to sell mitigates the negative effect of installed bases on innovation incentives. To see the intuition, consider the effects on the two commercialization routes.

Entry. The value for the entrepreneur of entering the industry is inversely U-shaped in network effects. At low levels of network effects, the entrant-as well as the incumbentsbenefit from stronger network effects as there is an increase in consumers' willingness to pay. When network effects become strong enough, however, the larger installed base of incumbents is more attractive to consumers so that the entrant starts losing consumers to incumbents. The entry profit decreases and, eventually, entry is not profitable and innovation incentives are non-existent.

Sale. The value of selling to incumbents is endogenously determined in the acquisition auction. Two equilibrium prices exist. One is an entry-deterring acquisition price. This price is paid when an incumbent makes the acquisition to prevent entry. The equilibrium price is the entrant's reservation price (the entry profit). The second equilibrium price is a preemptive acquisition price. This price is paid when incumbents compete to acquire the innovation, such as the case was when Google competed with Facebook and Apple to buy Waze. This price is determined by the difference in profits of acquiring the innovation relative to the profit when it is acquired by a rival incumbent. The preemptive acquisition price is strictly increasing in network effects when network effects are strong, since the profit as an acquirer increases in network effects and the profit as a non-acquirer decreases in network effects. The reason is that acquiring the innovation generates an asymmetry in expected network size between incumbents. This asymmetry is amplified 
by network effects and by installed bases, creating a demand-side synergy: by adding the initial user base of the entrepreneur to its own installed base, the acquirer obtains a strong market position as new consumers are attracted to the firm with the largest expected network. Network effects thus have a dual positive effect on the preemptive acquisition price.

When both commercialization routes are available, three regions exist. For weak network effects, entry takes place. For medium network effects, one incumbent will deter entry by acquiring the entrepreneurial firm at her reservation price. For strong network effects, however, incumbents compete fiercely to prevent rivals from obtaining the innovation and the acquisition price is driven up to the preemptive value. Since the entry value in this region is decreasing in network effects while the preemptive value is increasing in network effects, a sale to an incumbent does not only avoid the entry barriers created by installed bases - it also allows the entrepreneur to exploit the rivalry between incumbents to secure a high reward to innovating. Paradoxically, the incentive to innovate for sale is then the greatest when network effects and large incumbent installed bases create the most harmful innovation incentives under entry. It also implies that network effects promote acquisitions over entry. We predict a substantial takeover activity in markets with network effects as incumbents fight to obtain innovations and the initial user base attached to them. And entrepreneurs should have incentives to innovate for sale, rather than innovate for entry. If the network effects are strong, the shift towards commercialization through a sale to an incumbent from entry also leads to a higher consumer surplus. Total output in the market expands because of the demand-side synergy between the incumbent's installed base and the entrant's initial user base.

This paper contributes to the literature on network effects by developing a model of competition in network industries that allows for innovation efforts by an independent entrepreneur and that endogenously determines whether an acquisition or entry into the industry takes place. ${ }^{2}$ In the literature on network effects, papers such as Katz and Shapiro (1985), Farrell and Saloner (1985), Farrell and Saloner (1986), and Katz and Shapiro (1992) have studied how expectations and installed bases can lead to too fast or too slow movement to a new technology. ${ }^{3}$ In particular, as emphasized in Farrell and Klemperer (2007), installed bases can create a barrier to entry. We start from the network model in Katz and Shapiro (1985), bring in installed bases and asymmetries as in Cremer et al. (2000) or Malueg and Schwartz (2006), and embed an innovation and

\footnotetext{
${ }^{2}$ For an overview of the literature on network effects, see Economides (1996) or Farrell and Klemperer (2007).

${ }^{3}$ In Section 4.1, we show that our results also hold when the entrepreneur brings an innovation which reduces the marginal cost.
} 
commercialization stage from Norbäck et al. (2011) and Norbäck and Persson (2012). This makes it possible for us to show that network effects and installed bases need not restrict the innovation incentives for entrepreneurial firms due to a demand-side synergy between the initial user base of the entrepreneur and the installed base of incumbents.

The literature on the commercialization of innovations has shown that commercialization by sale (or by licensing) is more likely when the entry costs are high, the entrepreneurial firm lacks complementary assets, brokers facilitating trade are available, the expropriation problem associated with asset transfers is low, and the intensity of product market competition is high (Anton and Yao (1994), Gans and Stern (2000), Gans et al. (2002) and Gans and Stern (2003)). Two papers close to this one are Norbäck et al. (2011) and Norbäck and Persson (2012). ${ }^{4}$ Norbäck et al. (2011) develop a theory of commercialization of entrepreneurial innovations into oligopoly, and show that an innovation of higher quality is more likely to be sold to incumbents. Norbäck and Persson (2012) describe how competition policy affects entry and acquisition incentives when preemptive bidding for entrepreneurs is possible. We add to this literature by examining how network effects affect the commercialization route and equilibrium acquisition prices.

Finally, and more generally, our paper relates to the work on auctions with externalities by Jehiel et al. (1996), Jehiel and Moldovanu (1996) and Jehiel and Moldovanu (2000). A seminal analysis of this mechanism in the context of preemptive patenting is given in Gilbert and Newbery (1982) and Katz and Shapiro (1986), but we are not aware of any work that ties this literature to acquisitions of startups in network industries.

We have organized the paper as follows. The next section describes and solves the model. Section 3 presents the central propositions of the paper by undertaking comparative statics on the strength of network effects. We present extensions in Section 4 and offer concluding remarks in Section 5.

\section{The model}

There are initially $n \geq 2$ incumbents with incompatible products and installed bases $b$ on the market. The installed base of each incumbent represents the mass of consumers who are locked in to the incumbent's product and cannot switch to other firms. In Stage 1 , an entrepreneur undertakes an effort to increase the probability $\rho$ of discovering an innovation. If the innovation effort succeeds, the entrepreneur is able to attract an initial base of $k$ "locked-in" consumers. In Stage 2, the entrepreneur decides whether to sell

\footnotetext{
${ }^{4}$ See also related work combining downstream oligopoly interaction with an auction with externalities in Norbäck and Persson (2009) and Norbäck et al. (2010).
} 
the innovation-and the associated initial user base $k$-to an incumbent firm or enter the market. ${ }^{5}$ In Stage 3, product market competition for new consumers takes place.

We will maintain the following assumption in the rest of the paper.

Assumption 1 The installed base of the entrant is smaller than that of the incumbents: $0<k<b$.

Assumption 1 is natural given that incumbents have been around for a longer time than the entrant and so been able to build a larger installed base.

\subsection{Stage 3: Product market competition}

\subsubsection{Demand structure}

The demand structure is adopted from Katz and Shapiro (1985), extended to incorporate installed bases as in Cremer et al. (2000) or Malueg and Schwartz (2006). The inverse demand for firm $j$ by new consumers is

$$
p_{j}=T+z\left[\bar{q}_{j}+b_{j}\right]-Q,
$$

where $T$ is the demand intercept, $z \in[0,1)$ is the network effect (or network strength), $Q=\sum_{j}^{m} q_{j}$ the aggregate output, and $b_{j}$ the installed base. The installed base is $b_{j}=b+k$ if firm $j$ is an incumbent firm in possession of the installed base $k, b_{j}=b$ if firm $j$ is a non-acquiring incumbent firm and $b_{j}=k$ if firm $j$ is the entrepreneur. Consumers' expectations of the firm's output is $\bar{q}_{j}$. The number of firms is $m=n+1$ under entry and $m=n$ under an acquisition or if the innovation fails.

The profit of firm $j$ is

$$
\pi_{j}\left(q_{j}, q_{-j}\right)=\left[p_{j}-c\right] q_{j}
$$

where $c$ is a symmetric marginal cost, $q_{j}$ are the sales of firm $j$ and $q_{-j}$ are the sales of its rivals. Taking consumers expectations' as given, the optimal outputs are determined from the first-order conditions

$$
\frac{\partial \pi_{j}}{\partial q_{j}}=p_{j}-c-q_{j}^{*}=0, \forall j
$$

where we assume that the usual stability and second-order conditions are fulfilled.

\footnotetext{
${ }^{5}$ There is a also a fixed cost of entry. For simplicity, we normalize the fixed cost of entry for a successful innovation to zero, $F_{E}=0$, and suppose that the fixed cost for the entrepreneur when failing, $F_{E}=F$, is sufficiently high to prevent entry.
} 
We prove in Appendix A.1 that there exists an interior Fulfilled Expectations Cournot Equilibrium, where consumers' expected network size corresponds to firms' optimal output decisions, and for which the market does not tip towards one firm: $Q^{*}=\sum_{j}^{m} q_{j}^{*}=$ $\bar{Q} .{ }^{6} \quad$ Defining $\Lambda=T-c, B=\sum_{j}^{m} b_{j}$ as the aggregate installed base, and assuming fulfilled expectations $\bar{q}_{j}=q_{j}^{*}$, we first derive total output

$$
Q^{*}=\frac{m \Lambda+z B}{m+1-z}
$$

by substituting (1) into (3), and summing over all $m$ firms. Substituting (1) and (4) into (3), and then applying fulfilled expectations $\bar{q}_{j}(l)=q_{j}^{*}(l)$, we can then solve for firm $j^{\prime} s$ output

$$
q_{j}^{*}=\frac{\Lambda+z b_{j}-Q^{*}}{1-z} .
$$

From (1) and (3), firm profits are finally quadratic in output, $\pi_{j}^{*}=\left[q_{j}^{*}\right]^{2}$.

How do profits respond to network effects? Define $\varphi_{j}^{*}=\frac{q_{j}^{*}+b_{j}}{Q^{*}+B}$ as the relative network size of firm $j$. From (4), (5) and $\pi_{j}^{*}=\left[q_{j}^{*}\right]^{2}$, we can then derive

$$
\frac{d \pi_{j}^{*}}{d z}=2\left(\frac{Q^{*}+B}{1-z}\right)\left(\varphi_{j}^{*}-\frac{1}{m+1-z}\right) q_{j}^{*}
$$

Equation 6 tells us that the profit of a firm will increase in network effects if and only if it has a sufficiently large relative network size, $\varphi_{j}^{*}$. This is somewhat surprising at first since equation 1 reveals that for given size of the firm's expected network size, $\bar{q}_{j}+b_{j}$, consumers willingness to pay increase in network effects. However, since consumers attach a value to the size of the firm's network, if stronger network effects also induce a decline in the firm's expected network size and a growth of rival' networks, consumers willingness to pay will decline. Equation 6 thus shows that when network effects increase, firm $j$ will only be able to attract new consumers if it has an initial relative network size which is sufficiently large. ${ }^{7}$ This, in turn, will crucially depend on the size of its installed base of locked-in consumers.

When all firms have symmetric installed bases, network effects always increase the profits of firm $j$ (i.e. $\varphi_{j}^{*}=1 / m>\frac{1}{m+1-z}$ in equation 6 ). However, when installed

\footnotetext{
${ }^{6}$ In the remainder of the analysis, we will focus on this interior equilibrium. As in Malueg and Schwartz (2006), there can exist other equilibria in which the market tips towards any of the $n$ firms if network effects are strong enough and consumer coordinate on that firm. We focus on the interior equilibrium to highlight how network effects on the margin affect the mode of commercialization and innovation incentives of entreprenurs.

${ }^{7}$ For a more formal derivation, see Appendix A.2.
} 
bases make firms asymmetric, if firm $j$ has a sufficiently small relative network size (i.e. $\varphi_{j}^{*}<\frac{1}{m+1-z}$ in equation 6) increasing network effects will decrease its profits as new consumers are instead attracted to the rivals' larger networks.

\subsubsection{Firms' profits and network effects}

Consider now the profits of the firms depending on the outcome of stage 1 and stage 2 of the game. Because of symmetry between firms, we can reduce the number of profit functions to keep track of. If the entrepreneur failed with the innovation, profits of incumbents in the industry are $\pi_{N}^{*}$. If an acquisition in stage two takes place, we denote acquiring incumbents profits by $\pi_{A}^{*}$ and non-acquiring incumbent profits by $\pi_{N A}^{*}$. If entry takes place in stage two, the entrants profits are denoted $\pi_{E}^{*}$ and the non-acquiring incumbents profits $\pi_{N E}^{*}$. We have the following Lemma.

Lemma 1 Firm's profits are affected by network effect as follows.

\section{1) If the entrant fails to discover the innovation:}

(i) The profit of an incumbent $\pi_{N}^{*}$ is strictly increasing in $z: \frac{d \pi_{N}^{*}}{d z}>0$.

\section{2) If the entrant is acquired in stage 2:}

(ii) The profit of an acquiring incumbent $\pi_{A}^{*}$ is strictly increasing in $z: \frac{d \pi_{A}^{*}}{d z}>0$.

(iii) The profit of an non-acquiring incumbent $\pi_{N A}^{*}$ is inversely U-shaped in $z: \frac{d \pi_{N A}^{*}}{d z}>0$ for $z<z_{N A}$ and $\frac{d \pi_{N A}^{*}}{d z}<0$ for $z>z_{N A}$.

\section{3) If the entrant enters in stage 2:}

(iv) The profit of the entrant $\pi_{E}^{*}$ is inversely U-shaped in $z: \frac{d \pi_{E}^{*}}{d z}>0$ for $z<z_{E}$ and $\frac{d \pi_{E}^{*}}{d z}<0$ for $z>z_{E}$.

(v) The profit of a non-acquiring incumbent $\pi_{N E}^{*}$ is strictly increasing in $z: \frac{d \pi_{N E}^{*}}{d z}>0$.

Proof. See the Appendix.

The intuition behind Lemma 1, which is also illustrated in Figure 1 for one set of parameter values, is as follows.

Profits without the innovation. If the entrant fails to discover the innovation, installed bases are $b$ for all $n$ incumbent firms in the industry. As all firms are symmetric and hold a sufficiently large relative network size $\varphi_{j}^{*}=\frac{1}{n}$, it follows directly from (6) that incumbent profits $\pi_{N}^{*}$ are strictly increasing in $z$. 
Profits under an acquisition. If the entrant is acquired in stage 2, the acquisition will create an asymmetry among the $n$ firms in the industry with the acquiring incumbent having an installed base of $b+k$ and the non-acquiring incumbents having installed bases of $b$. The larger installed base gives the acquiring incumbent an advantage over rivals that manifests itself in a larger relative installed base: $\varphi_{A}^{*}>1 / n>\varphi_{N A}^{*}$. The advantage becomes greater as network effects increase, so $\pi_{A}^{*}$ is strictly increasing in $z$. For the non-acquiring incumbents, stronger network effects initially raise their profits as network effects are relatively unimportant (for $z<z_{N A}$ ). However, at increasing network effects consumers' attraction to the larger network of the acquirer is reinforced. When the network effects exceed $z_{N A}$, consumers correctly infer that the networks of non-acquiring incumbents will decrease as the acquiring incumbent's network expands. The profit of non-acquiring incumbents then decreases in the network effect $\left(z>z_{N A}\right)$.

Profits under entry. If the entrant enters in stage 2, entry will also create an asymmetry among the now $m=n+1$ firms in the industry. The installed base of the entrant equals $k$ and the installed base of each of the incumbents equals $b$. The asymmetry is now such that the entrepreneur will hold a relatively smaller network share than incumbent rivals, $\varphi_{E}^{*}<1 /(n+1)<\varphi_{N E}^{*}$. The entrepreneur is then less able attract new consumers who are drawn towards the incumbents' larger installed bases, $b>k$. Due to their relatively larger networks, incumbent rivals will always see their profits $\pi_{N E}^{*}$ increase in network effects (equation 6 is always positive for incumbents). When network effects are less than $z_{E}$, the asymmetry in installed bases is less important for new consumers and the profit increases in network effects for the entrant (equation 6 is positive for $z<z_{E}$ ). At networks effects stronger than $z_{E}$, new consumers' attraction to the larger networks of the incumbents implies that the entrepreneur's profit decreases in network effects (equation 6 is negative for $z>z_{E}$ ).

Let us end this section by comparing the profits of a non-acquiring incumbent under acquisition and entry. The following corollary holds:

Corollary 1 There exists a $\hat{z}$ such that the profit as a non-acquirer is lower under entry $\pi_{N E}^{*}<\pi_{N A}^{*}$ for low network effects, $z<\hat{z}$, whereas the profit as a non-acquirer is higher under entry $\pi_{N E}^{*}>\pi_{N A}^{*}$ for strong network effects, $z>\hat{z}$.

Proof. See the Appendix.

Network effects implies that the profits for a non-acquirer under an acquisition may be lower than those under entry $\left(\pi_{N A}^{*}<\pi_{N E}^{*}\right)$. This is surprising since entry increases 


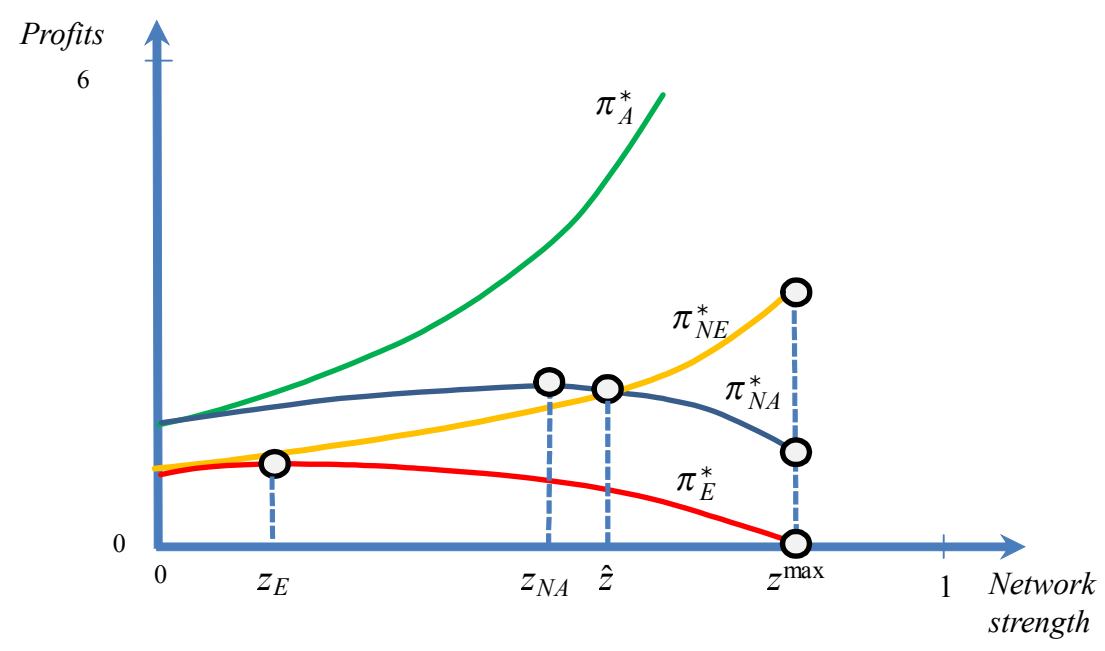

Figure 1: Illustrating the reduced profit functions. Parameter values at $n=3, b=1$, $\Lambda=T-c=5$, and $k=0.6$.

competition in the market (we go from $n$ to $n+1$ firms). The reason for this effect is that the asymmetry in installed bases under an acquisitions implies that network effects act like a synergy for the acquirer. By adding the installed base $k$ of the entrepreneur to its incumbent base $b$, the acquirer obtains a strong market position as new consumers are attracted to the firm with the largest network. In contrast, since the entrant has a smaller installed base than incumbents $k<b$, incumbents can attract consumers from the entrant when network effects are strong. This latter effect mitigates the effect of increased competition from entry on the profits of non-acquirers.

\subsection{Stage 2: the acquisition/entry decision}

Having solved for how network effects and the commercialization route affect product market profits, we now turn to the commercialization decision in Stage 2 to characterize the equilibrium ownership structure, the acquisition price and the entrepreneurial reward given product market profits (Lemma 2). Whereas Stage 3 closely followed Katz and Shapiro (1985), extended to include installed bases as in Cremer et al. (2000) and Malueg and Schwartz (2006), Stage 2 and Stage 1 closely follow Norbäck et al. (2011) and Norbäck and Persson (2012).

Given a successful innovation, there is first an entry-acquisition game where the entrepreneur can decide either to sell the innovation to one of the incumbents or to keep 
the innovation. If she decides to keep the innovation, she can enter the market at an entry cost, or choose not to commercialize. In our analysis, we want to examine how entry barriers, emerging from the combination of network effects and large installed bases of incumbents, affect the incentive for an entrepreneur to innovate and commercialize new innovations. Without loss of generality, we then assume that succeeding with the innovation also reduces the fixed cost of entry. We normalize the fixed cost of entry for a successful innovation to zero: $F_{E}=0$ and suppose that the fixed cost for the entrepreneur when failing $F_{N}=F$ is sufficiently high to prevent entry. ${ }^{8}$

Because we want to focus on interior solutions in which the acquisition does not lead to a monopoly, we also impose the following assumption.

Assumption 2 Network effects are not too strong. Given a succesful innovation, monopolization does not occur after an acquisition and entry is always profitable: $z \in$ $\left[0, z^{\max }\right)$, with $z^{\max }$ defined as $z^{\max }=\min \left\{z_{N A}^{\max }, z_{E}^{\max }\right\}$ where $\pi_{N A}^{*}\left(z_{N A}^{\max }\right)=0$ and $\pi_{E}^{*}\left(z_{E}^{\max }\right)=0$.

The acquisition game, which occurs in the early period in Stage 2, is an auction where $n$ incumbents simultaneously post bids, and the entrepreneur then either accepts or rejects these bids. Each incumbent announces a bid, $b_{i}$, for the innovation. $\mathbf{b}=$ $\left(b_{1}, . . b_{i} . ., b_{n}\right) \in R^{n}$ is the vector of these bids. Following the announcement of $\mathbf{b}$, the innovation may be sold to one of the incumbents at the bid price, or remain with the entrepreneur. If more than one bid is accepted, the bidder with the highest bid obtains the innovation. If there is more than one incumbent with such a bid, each obtains the innovation with equal probability. The acquisition auction is solved by finding Nash equilibria in undominated pure strategies. There is a smallest amount $\varepsilon$ chosen such that all inequalities are preserved if $\varepsilon$ is added or subtracted.

We can now specify firms' valuations in the acquisition game in the early period of Stage 2 .

- $v_{i i}$ is the value for an incumbent of obtaining the entrepreneur's initial user base, when a rival incumbent would otherwise obtain it:

$$
v_{i i}=\pi_{A}^{*}-\pi_{N A}^{*} .
$$

\footnotetext{
${ }^{8}$ With $n+1$ firms on the market, we thus assume that $\pi_{E}^{*}<F$. Since incumbents have already sunk their entry cost, they have strictly positive profits, $\pi_{N}^{*}>0$. It is tedious but straightforward to relax the assumption of fixed cost savings to have $F_{E}=F$. However, this does not change our main results but requires more cases to keep track of since profitable entry might require a sufficiently large base of initial users, $k$.
} 
- $v_{i e}$ is the value of obtaining the entrepreneur's initial user base for an incumbent, when the entrepreneur would otherwise enter the market:

$$
v_{i e}=\pi_{A}^{*}-\pi_{N E}^{*}
$$

The profit for an incumbent of not obtaining the entrepreneur's initial user base is different in this case, due to the change of identity of the firm that would otherwise possess it.

- $v_{e}$ is the value for the entrepreneur of keeping the entrepreneur's initial user base and entering the market:

$$
v_{e}=\pi_{E}^{*}
$$

We can now proceed to solve for the equilibrium ownership structure. Since incumbents are symmetric, the valuations can be ordered in six different ways, as shown in Table 1. These inequalities are useful for solving the model and illustrating the results.

Lemma 2 Equilibrium ownership, acquisition price $S^{*}$ and entrepreneurial reward $R_{E}$ are described in Table 1:

Table 1: The equilibrium ownership structure and the acquisition price.

\begin{tabular}{ccccc}
\hline Inequality: & Definition: & Ownership & Acquisition price, $S^{*}:$ & Reward, $R_{E}:$ \\
\hline$I 1:$ & $v_{i i}>v_{i e}>v_{e}$ & Incumbent & $v_{i i}$ & $v_{i i}$ \\
$I 2:$ & $v_{i i}>v_{e}>v_{i e}$ & Incumbent/Entrant & $v_{i i}$ & $v_{i i}$ or $v_{e}$ \\
$I 3:$ & $v_{i e}>v_{i i}>v_{e}$ & Incumbent & $v_{i i}$ & $v_{i i}$ \\
$I 4:$ & $v_{i e}>v_{e}>v_{i i}$ & Incumbent & $v_{e}$ & $v_{e}$ \\
$I 5:$ & $v_{e}>v_{i i}>v_{i e}$ & Entrant &. & $v_{e}$ \\
$I 6:$ & $v_{e}>v_{i e}>v_{i i}$ & Entrant &. & $v_{e}$ \\
\hline
\end{tabular}

Proof. See the Appendix.

Lemma 2 shows that when one of the inequalities $I 1, I 3$, or $I 4$ holds, $k$ is obtained by one of the incumbents. Under $I 1$ and $I 3$, incumbents have a strong incentive to preempt rival incumbents from acquiring the entrepreneur's initial user base $k$ since $v_{i i}>v_{e}$. This implies that incumbents will initiate a bidding competition over $k$ resulting in the acquiring incumbent paying the acquisition price $S=v_{i i}$ which is strictly higher than the entrepreneur's reservation price $v_{e}$. This implies that the entrepreneur is willing to sell out to an incumbent. Under $I 4$, the value of acquiring $k$ for an incumbent largely comes from the vale of deterring entry by the entrepreneurs. In this situation, no bidding competition occurs and the acquiring incumbent need only pay the entrepreneur's 
reservation price, i.e. $S=v_{e}$ under $I 4$. When $I 5$ or $I 6$ holds, the entrepreneur enters the market since incumbents are then not so negatively affected by entry or by a rival incumbent acquiring $k$. When $I 2$ holds, there exist multiple equilibria. There is one where all incumbents coordinate on not creating a bidding war over $k$, and the entrepreneur keeps its $k$. The other is an equilibrium where the incumbents cannot coordinate on avoiding a bidding competition and end up acquiring $k$ at a preemptive value, i.e. $S=v_{i i}$. The last column summarizes the reward $R_{E}$ accruing to the entrepreneur.

\subsection{Stage 1: innovation by the entrepreneurial firm}

In Stage 1, the entrepreneur decides on innovation intensity given the reward determined in Stage 2. The entrepreneur undertakes an effort to discover the innovation by selecting the probability $\rho \in[0,1]$ of discovering the innovation. If she succeeds, her innovation will attract an initial user base of $k$ consumers (which are locked-in in Stage 3, where firms compete for new consumers). Let the effort cost $y(\rho)$ be an increasingly increasing function of the success probability: $y^{\prime}(\rho)>0$ and $y^{\prime \prime}(\rho)>0$. The expected net profit of undertaking effort to discover an innovation is thus $\bar{\Pi}_{E}=\rho R_{E}-y(\rho)$. The optimal success probability as a function of the reward $\rho^{*}\left(R_{E}\right)$ is implicitly given from the firstorder condition

$$
\frac{d \bar{\Pi}_{E}}{d \rho}=R_{E}-y^{\prime}\left(\rho^{*}\right)=0,
$$

with the associated second-order condition equal to $\frac{d^{2} \bar{\Pi}_{E}}{d \rho^{2}}=-y^{\prime \prime}(\rho)<0$. We have the following Lemma:

Lemma 3 The equilibrium probability of successfully innovating in Stage 1 increases with the reward: $d \rho^{*} / d R_{E}>0$.

This Lemma, obtained by using the implicit function theorem, simply states that the entrepreneur's innovation incentives (the optimal success probability) is increasing in the reward to innovation determined in the commercialization stage (Stage 2).

\section{How is the commercialization route and innovation in- centives affected by network effects?}

Having set up and solved the model, we now perform comparative statics with respect to the strength of network effects. We will show that increases in network effects promote acquisitions over entry (Proposition 1 and Proposition 2), increase the acquisition 
premium (Proposition 3), and thereby promote the innovation incentives (Proposition $4)$.

\subsection{Strong network effects promote acquisitions}

We start by showing that network effects promote acquisitions over entry. Define $z^{E D} \in$ $(0,1)$ such that $v_{i e}\left(z^{E D}\right)=v_{e}\left(z^{E D}\right)$ and $z^{P E} \in(0,1)$ such that $v_{i i}\left(z^{P E}\right)=v_{e}\left(z^{P E}\right)$. Moreover, define $z_{A}=\min \left\{z^{E D}, z^{P E}\right\}$ and $z_{B}=\max \left\{z^{E D}, z^{P E}\right\}$. We can then state the following Proposition:

Proposition 1 (i) For sufficiently small network effects, there will be commercialization by entry: there exists an $z_{A} \in(0,1)$ such that for all $z \in\left(0, z_{A}\right)$ entry will occur.

(ii) For sufficiently strong network effects, commercialization by sale under bidding competition emerges: there exists a $z_{B} \in(0,1)$ such that $z \in\left(z_{B}, z^{\max }\right)$ implies an acquisitions at price $S^{*}=v_{i i}$ takes place.

Proof. See Appendix

Parts (i) and (ii) of Proposition 1 state the main result of the paper: entry occurs at low network effects and commercialization by sale under bidding competition occurs at strong network effects.

In the intermediate region of parameter values of $z, z \in\left[z_{A}, z_{B}\right]$, we cannot establish a monotone relationship between the size of network effects and the commercialization route (entry or sale) without any restrictions on the parameter values in the model. To this end, we focus on parameter values which ensure that weak network effects are associated with entry and strong network effects are associated with sale also in the interval $z \in\left[z_{A}, z_{B}\right]{ }^{9}$ Moreover, these restrictions enable us to describe each possible outcome of the acquisition game derived in Lemma 2 (entry (I6), entry deterring acquisitions (I4), and preemptive acquisitions (I3) and (I1)) and they enable us to describe the economic intuition for how the equilibrium ownership of the invention depends on the level of network effects. As will be seen, the analysis described below will also clearly spell out the economic forces explaining the results stated in Proposition 1.

More specifically, we assume:

\footnotetext{
${ }^{9}$ Without these restrictions, we may possibly have (i) an equilibrium without entry deterring acquisition (no I4), and only have entry at weak network effects and preemptive acquisitions for strong network effects. (ii) an equilibrium where, in the interval, $z \in\left[z_{A}, z_{B}\right]$, we may have entry deterring acquisitions (I4) for weak network effects in this interval, but then, for stronger network effects, we will reach I2 and thus having multiple equilibria (entry or sale), hereby breaking the monotone relationship between network strength and commercialization route. However, we have not been able to find any parameter values consistent with such an equilibrium.
} 
Assumption $3 z^{E D}$ is unique with $z^{E D}<z^{P E}$.

Figure 2 is drawn for parameter values $n=3, b=1, \Lambda=T-c=5$ and $k=0.6$. This combination of parameters fulfill Assumption 3, and thus establishes the existence of at least one instance with $z^{E D}$ being unique and for which $z^{E D}<z^{P E}$. Using Assumption 3 , we can relate the commercialization decision of a successful innovation to network effects.

Proposition 2 Under Assumption 3:

(i) entry takes place if $z \in\left[0, z^{E D}\right)$,

(ii) an entry deterring acquisition at price $S^{*}=v_{e}$ takes place for $z \in\left[z^{E D}, z^{P E}\right)$, and

(iii) a preemptive acquisition at price $S^{*}=v_{i i}$ occurs for $z>z^{P E}$.

The proof of Proposition 2 is illustrated in Figure 2. First, note that Lemma 1 showed that $v_{e}=\pi_{E}^{*}$ increases for weak network effects but then decreases when the network effects are strong as consumers are increasingly attracted to the incumbents' larger installed bases of locked-in consumers. The inverse U-shape of $v_{e}$ is shown in Figure 2 .

Turn next to the incumbents' valuations. Starting with the preemptive valuation in (7), we have

$$
\frac{d v_{i i}}{d z}=\frac{d \pi_{A}^{*}}{\underset{(+)}{d z}}-\frac{d \pi_{N A}^{*}}{d z}>0
$$

For strong network effects, $z>z^{N A}$, Lemma 1 implies that incumbents' preemptive willingness to pay increases in the network effects. This is due to the incentive to obtain a strong position as an acquirer (as consumers are attracted to the larger network), but also from the incentive to avoid a weak position as a non-acquirer (as consumers shy away from a smaller network). In the proof of Proposition 1 in the Appendix, we also show that an incumbent's preemptive valuation $v_{i i}$ is strictly increasing in network effects for network effects that are weaker than $z^{N A}$ as the increase in profits for the acquirer is larger than the increase in profits as a non-acquirer. Thus, an incumbent's preemptive valuation is strictly increasing in networks effects, $\frac{d v_{i i}}{d z}>0$ (Figure 2(ii)). But then, since the reservation price $v_{e}$ is decreasing in network effects for strong network effects, the preemptive valuation must also exceed the reservation price $v_{i i}>v_{e}$ at sufficiently strong network effects. Furthermore, as also shown in the Appendix, the entry deterring valuation is strictly positive for strong network effects, i.e. $v_{i e}=\pi_{A}^{*}-\pi_{N E}^{*}>0$ will hold when $z$ becomes large enough. Intuitively, while the entrepreneur's output decreases in network effects benefitting symmetric incumbents under entry, network effects create 


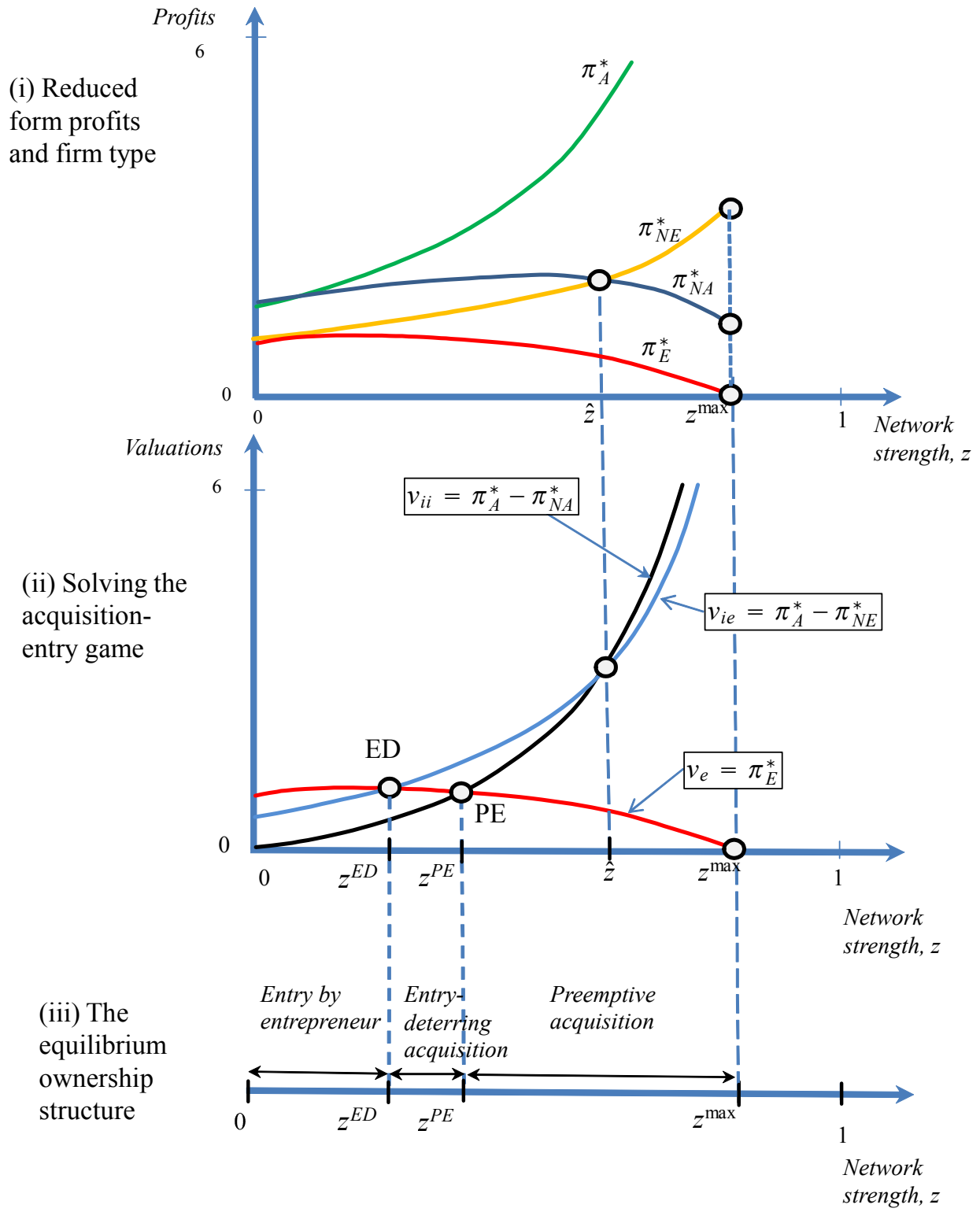

Figure 2: Deriving the equilibrium ownership structure. Parameter values set to $n=3$, $b=1, \Lambda=T-c=5$ and $k=0.6$. 
an even larger advantage for the acquiring incumbent since this firm holds the largest installed base. It then follows that also the entry-deterring valuation must exceed the reservation price at $v_{i e}>v_{e}$ at sufficiently strong network effects.

From Corollary 1, we know that the preemptive valuation $v_{i i}$ will exceed the entrydeterring valuation $v_{i e}$ when the network effects become stronger than $\hat{z} \cdot{ }^{10}$ As illustrated in Figure 2(ii), Assumption 3 then implies that $v_{i i}>v_{e}$ and $v_{i e}>v_{e}$ hold when the networks effects are stronger than $z^{P E}$. But then, since $v_{i e}>v_{e}$, incumbents always have an incentive to bid $v_{e}$ for to obtain $k$. However, if an incumbent bids $v_{e}$, rivals always have an incentive to bid more since $v_{i i}>v_{e}$. Indeed, as incumbents desire to have the largest network of locked-in consumers in order to attract new consumers and steal consumers from rivals, the bidding competition will drive the acquisition price all the way to the preemptive valuation, $v_{i i}$. Thus, as shown in Figure 2(iii), for $z>z^{P E}$, a preemptive acquisition occurs at the acquisition price $S^{*}=v_{i i}$ (inequality I1 in Table 1).

Then, turn to the opposite case when network effect are weak-or even absent. When network effects are absent, equation (1) implies that installed bases do not affect consumers' willingness to pay and all firms are symmetric. From (7) it then follows that the preemptive valuation is zero $\left(v_{i i}=0\right)$. In the Appendix, we also show that $v_{e}>v_{i e}>0$ holds at $z=0$. Incumbents then have an incentive to acquire the entrepreneurial firm to prevent entry, but without synergies from network effects, an acquisition is not profitable. The latter result is known from Salant et al. (1983). Salant et al. (1983) point out that when there are several incumbents in the market, the non-acquiring incumbents will expand their business when a merger takes place (as compared to the situation with entry). This implies that the market share of the merged entities will decrease substantially. Thus, without synergies, the acquisition (merger) is unprofitable. Assumption $3(\mathrm{i})$ then implies that there must exist a region $z \in\left[0, z^{E D}\right)$ where $v_{e}>v_{i e}>v_{i i}$ holds. Thus, as illustrated in Figures 2 (ii) and (iii), the entrepreneur will then enter the market in this region (inequality I6 in Table 1 holds).

Finally, under Assumption 3(ii), there will also exist a region $z \in\left[z^{E D}, z^{P E}\right)$ where $v_{i e}>v_{e}>v_{i i}$ holds. An entry-deterring acquisition at the acquisition price $S^{*}=v_{e}$ now occurs at $z=z^{E D}$ since $v_{i e}>v_{e}$. Other incumbents will not preempt a rival acquisition since the net value of preemption is negative, $v_{i i}-v_{e}<0$. Thus, as shown in Figure 2(iii), the entrepreneurial firm will be acquired at price $S^{*}=v_{e}$ in the region $z \in\left[z^{E D}, z^{P E}\right)$

\footnotetext{
${ }^{10}$ Once more, the reason is that the ownership of the initial user base of the entrepreneur creates a demand-side synergy with the acquirer's installed base through consumers' willingness to pay for a larger network. As the network effects increase, the competitive situation will be worse for a non-acquirer under an acquisition than under entry, despite the fact that entry increases the number of firms.
} 
(inequality I4 in Table 1).

\subsection{Strong network effects increase the acquisition premium}

Given that an acquisition takes place, how do network effects affect the equilibrium acquisition price and premium? Define the acquisition premium as the acquisition price net the reservation price, $S^{*}-v_{e}$. Then, we have the following proposition:

Proposition 3 The acquisition premium increases in network effects: under Assumption 3 and $z^{P E}>z_{E}$, we have $d\left(v_{i i}-v_{e}\right) / d z>0$.

We know that when the network effects become sufficiently strong, a further increase in network effects reduces $v_{e}$ because new consumers find it more attractive to belong to the incumbents' larger network. On the other hand, when one incumbent obtains the entrepreneur's installed base, the acquirer holds the largest installed base and will attract the most new consumers. As illustrated in Figure 2(iii), when the network effects become sufficiently strong, the preemptive valuation $v_{i i}=\pi_{A}^{*}-\pi_{N A}^{*}$ increases strongly in $z$, while the entrepreneur's reservation price $v_{e}=\pi_{E}^{*}$ decreases in $z$. This increases the acquisition premium $\left(v_{i i}-v_{e}\right)$.

To sum up, Proposition 3 gives an intuition for why acquisition prices can be high in network industries: acquiring an innovation gives an incumbent a larger lead over rivals at the same time as preventing a rival from acquiring the innovation.

\subsection{Strong network effects increase innovation incentives}

We now turn to the main message of the paper: the option of selling out to an incumbent increases the innovation incentives for entrepreneurs, in particular when network effects are strong and incumbents preemptively outbid each other. We can state the following lemma.

Lemma 4 When innovating for entry, innovation incentives will decrease in network effects $d \rho^{*} / d z<0$ when the network effects become sufficiently large, $z>z_{E}$.

That network effects create barriers to entry has previously been noted in the literature (see, for example, the survey by Farrell and Klemperer (2007)). However, our model suggests that while innovation incentives for entry are reduced by strong network effects, network effects may significantly boost the entrepreneur's incentive to innovate when commercialization takes place through a sale. We have the following proposition concerning the entrepreneurial firm's innovation incentives under sale. 


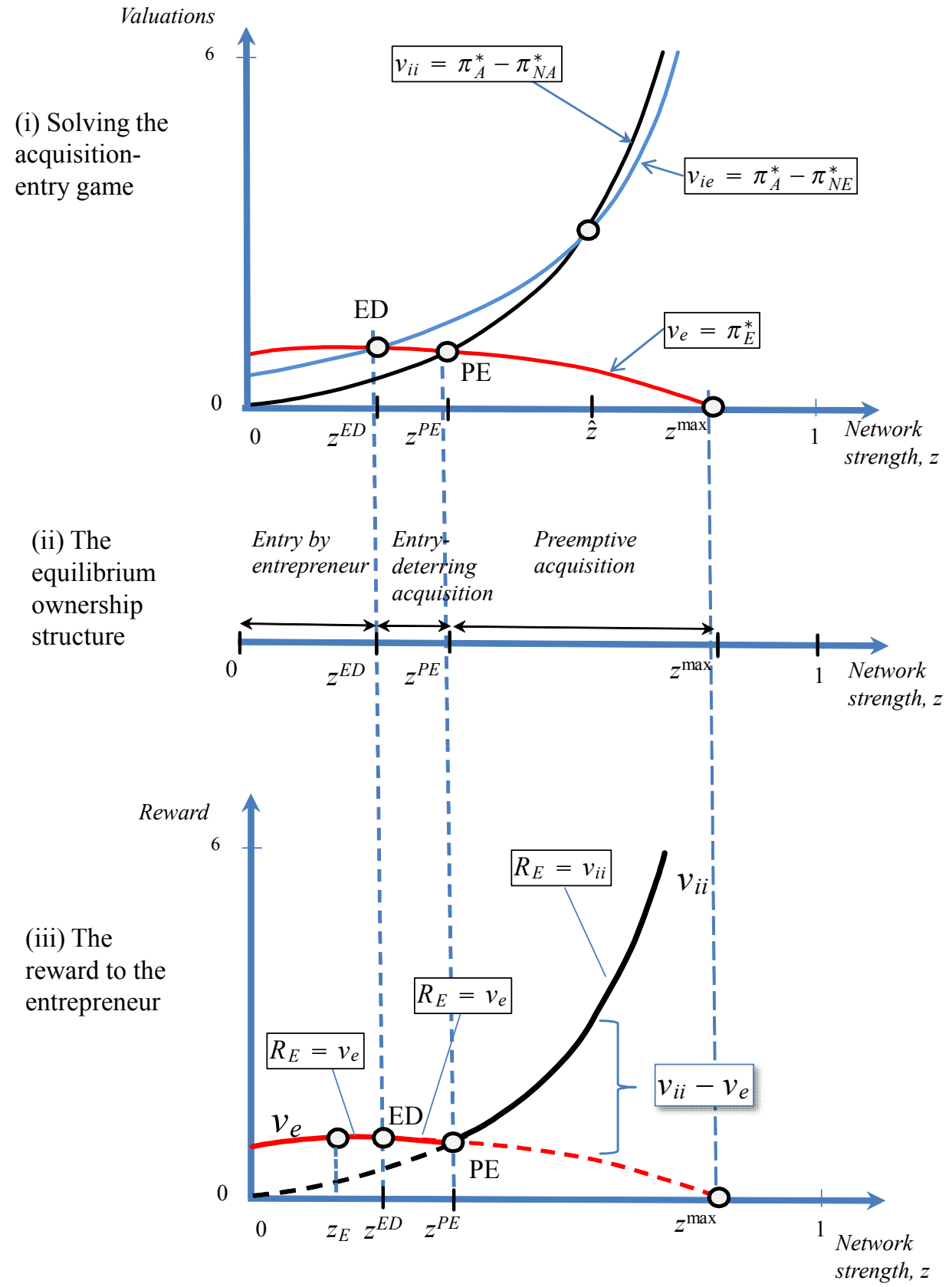

Figure 3: Deriving the reward to innovation. Parameter values at $n=3, b=1, \Lambda=$ $T-c=5$ and $k=0.6$. 
Proposition 4 Assume that Assumption 3 holds.

(i) Under preemptive acquisitions $\left(z \in\left(z^{P E}, z^{\max }\right)\right)$, entrepreneurial firms face stronger innovation incentives than under entry-deterring acquisitions or under entry: $\rho_{A}^{*}>\rho_{E}^{*}$. (ii) When the network effects become sufficiently large, they have a positive effect on innovation incentives under a sale with bidding competition but a negative effect under entry: $d \rho_{A}^{*} / d z>0<d \rho_{E}^{*} / d z$.

To see this, note that Lemma 3 showed that the research effort of the entrepreneur and hence, the probability of success $\rho^{*}$, increase in the reward $R_{E}$. Figure 3 (iii) depicts the reward $R_{E}$ as a function of network effects. The equilibrium reward $R_{E}$ is S-shaped. When the network effect is low $z \in\left(0, z^{E D}\right)$, entry will take place and the reward is $R_{E}=v_{e}$. This is also the reward if an entry deterring acquisition occurs in region $z \in\left[z^{E D}, z^{P E}\right)$ since $R_{E}=S^{*}=v_{e}$. From Lemma 1, we know that $v_{e}$ increases for weak network effects but then decreases when the network effects become sufficiently large. As illustrated in Figure 3(iii), the incentive to innovate (and hence the probability to succeed) is inversely U-shaped in the network effect. This mirrors the fact that when the network effect becomes sufficiently strong, consumers are drawn to the incumbents' larger networks which reduces the reward to innovating (this occurs in the region $z \in$ $\left(z_{E}, z^{P E}\right)$ in Figure 3(iii)). However, when the network effects are further increased, $z>z^{P E}$, a preemptive acquisition occurs. In this region, bidding competition among incumbents for the entrepreneurial firm causes the reward for innovation to be strictly greater than the reward for innovation under entry or an entry-deterring acquisition: $R_{E}=v_{i i}>v_{e}=R_{E}$. Since the probability of success $\rho^{*}$ is increasing in the reward $R_{E}$, it directly follows from Equation (11) that there will be a higher probability of success.

\section{Extensions}

This section provides a few extensions to our model. First, we show that the model can easily be recast as the innovation reducing the marginal cost of the entrant, rather than as generating an initial mass of users. Second, we show how larger installed bases of incumbents, given the size of the network effect, in fact themselves act to increase the acquisition price under preemptive bidding competition. Third, we point out that with strong network effects, consumers are better off when the innovation is commercialized through a sale to an incumbent. 


\subsection{Innovations reducing the marginal cost}

An alternative set up is that the innovation leads to a reduction of the marginal cost and the entrepreneur is unable to create an installed base of locked-in consumers. Then, only incumbents have installed bases $b$, say from historical sales. Letting $k$ capture marginal costs, suppose marginal costs for an acquiring incumbent is $c-k$, marginal costs for a non-acquiring incumbent $c$, and marginal costs in case of entry $c-k$. Then, it is straightforward to show that the change in the profit of a firm $j$ when network effects increase is

$$
\frac{d \pi_{j}}{d z}=2\left(\frac{Q^{*}+n b}{1-z}\right)\left(\varphi_{j}^{*}-\frac{1}{m+1-z]}\right) q_{j}^{*}
$$

Note that the same trade-offs still apply. In particular, it might be that even though the entrepreneur creates an innovation that reduces its marginal cost, this may not help in the competition for new consumers if less efficient incumbents hold large installed bases. Unless the innovation entails a very large reduction in the marginal cost, so that the incumbents' advantages in terms of their larger installed bases are swept away, Lemma 1 still applies and the profit under entry decreases in the network effect when the network effects become large. Thus, innovation incentives under entry will then decrease in network effects. However, as shown in Proposition 3, when selling the innovation, the entrepreneur can benefit as the innovation creates an asymmetry in the market: at a lower marginal cost, new consumers will infer that the acquiring incumbent will have the largest network. As suggested by Propositions 3 and 4, when the network effects increase, this will increase the bidding competition and increase the premium from selling which, in turn, increases the incentive to innovate.

\subsection{Incumbents' installed bases and innovation incentives}

Given the size of the network effects, larger installed bases of incumbents themselves act to increase the acquisition price under preemptive bidding competition. This is shown in the following proposition.

Proposition 5 The entrepreneur's innovation incentives decrease in incumbents' installed bases under entry, but increase in incumbents' installed bases under sale with bidding competition.

Proof. See the Appendix.

The intuition goes as follows. Larger installed bases of the incumbents will amplify the asymmetry between the incumbent and the entrant under entry (because $b$ increases 
and $k$ remains fixed), and between the acquiring incumbent and the non-acquiring incumbents under commercialization by sale (because of the demand-side synergy between $b$ and $k$ created by the network effects). Under entry, the profitability of the smaller entrant goes down as consumers are drawn to the larger incumbents' networks which are now relatively larger because of the larger installed base. Under a sale, and when the network effects are strong, the bidding competition between incumbents will intensify when there is an increase in installed bases. This is because of the demand-side synergy between $b$ and $k$, which increases the profit of the acquiring incumbent and decreases the profits of non-acquiring incumbents. The acquisition price determined by the value of preventing a rival from obtaining the installed base of the entrant thus increases when there is an increase in the installed bases of incumbents.

\subsection{Consumer welfare}

With strong network effects, consumers are better of when the innovation is acquired by an incumbent than if the entrepreneur had entered the market. From Katz and Shapiro (1985), the consumer surplus is:

$$
C S=\left[Q^{*}\right]^{2} / 2
$$

Let $C S_{A}$ be the consumer surplus when the innovation is acquired by an incumbent, and let $C S_{E}$ be the consumer surplus when the innovation is commercialized by entry.

Proposition 6 Consumers gain from commercialization by sale: If $z>\hat{z}$, an acquisition generates higher consumer surplus than entry does: $C S_{A}>C S_{E}$.

This result follows directly from Corollary 1 and equation 13. $C S_{A}>C S_{N}$ implies that the profit of a non-acquirer under sale must be lower than the profit of a non-acquirer under entry. In turn, this implies that total output must be higher under sale than under entry. Intuitively, under the asymmetric market structure when an incumbent acquires the installed base, the acquirer is so aggressive in attracting new consumers that new consumers will be better off from a sale if $z>\hat{z}$. Making use of (5), (7) and (8), we note that $Q_{A}^{*}>Q_{E}^{*}$ is fulfilled whenever the preemptive valuation exceeds the entry-deterring valuation, $v_{i i}>v_{i e}$. This proposition shows that avoiding entry barriers (created by installed bases and strong network effects) by selling the innovation (rather than choosing to enter the market) does not harm consumer welfare. 


\section{Concluding remarks}

In this paper, we have studied how innovation incentives in industries with installed bases and network effects are affected by bidding competition between incumbents for new entrepreneurial firms. We showed how the option of selling out to an incumbent increases the innovation incentives for entrepreneurs when the network effects are strong and incumbents compete to preemptively acquire innovations. Hence, network effects and installed bases do not necessarily restrict the innovation incentives.

As shown by the examples mentioned in the introduction (Apple's acquisition of Lala.com in 2010, the battle between Google and Facebook over Skype in 2011, and Google's acquisition of Waze in 2013), the bidding competition between incumbents for new entrepreneurial firms is common. What our paper underscores is that these bidding wars are likely to drive innovation incentives among young entrepreneurial firms, which dream of striking gold by selling out to an established incumbent. The large price tags attached to these acquisitions can be motivated by incompatibility, installed bases and the demand-side synergies between installed bases of incumbents and the entrant. Our model indicates that these demand-side synergies can lead to a higher consumer surplus than what entry into the market would have generated.

The model also gives rise to empirically testable predictions. Both the ratio of acquisitions to entry in network industries and total innovation output (e.g. patents) by potential innovative entrants should be higher the stronger are the network effects. Testing these predictions is a fruitful avenue for further research. The model could also be extended in several directions. Though not trivial and certainly cumbersome, one useful extension would be to study compatibility decisions of incumbents, entrants, and governments. Another extension would be to allow incumbents to innovate. Using data on Belgian manufacturing firms, Cassiman and Veugelers (2006) provide econometric evidence consistent with complementarity between acquiring inventions and internal R\&D. Escribano et al. (2009) use data on Spanish firms to show that this absorptive capacity is an important source of competitive advantage. 


\section{References}

Anton, J. J. and D. A. Yao (1994). Expropriation and inventions: Appropriable rents in the absence of property rights. American Economic Review 84, 190-209.

BusinessWeek (2010). Is Apple ready for merger mania? January 25, page 32.

Cassiman, B. and R. Veugelers (2006). In search of complementarity in innovation strategy: Internal r\&d and external knowledge acquisition. Management Science 52, 68-82.

Cremer, J., P. Rey, and J. Tirole (2000). Connectivity in the commercial internet. Journal of Industrial Economics 48, 433-72.

Economides, N. (1996). The economics of networks. International Journal of Industrial Organization 14, 673-699.

Economist (2013). Street plan. June 15.

Escribano, A., A. Fosfuri, and J. Tribo (2009). Managing external knowledge flows: The moderating role of absorptive capacity. Research Policy 38, 96-105.

Farrell, J. and P. Klemperer (2007). Coordination and Lock-In: Competition with Switching Costs and Network Effects., Volume 3 of Handbook of Industrial Organization, Chapter 31, pp. 1967-2072. Elsevier.

Farrell, J. and G. Saloner (1985). Standardization, compatibility, and innovation. RAND Journal of Economics 16, 70-83.

Farrell, J. and G. Saloner (1986). Installed base and compatibility: Innovation, product preannouncements, and predation. American Economic Review 76, 940-955.

Gans, J. S., D. H. Hsu, and S. Stern (2002). When does start-up innovation spur the gale of creative destruction? RAND Journal of Economics 33, 571-586.

Gans, J. S. and S. Stern (2000). Incumbency and R\&D incentives: Licensing the gale of creative destruction. Journal of Economics 83 Management Strategy 9, 485-511.

Gans, J. S. and S. Stern (2003). The product market and the market for "ideas": Commercialization strategies for technology entrants. Research Policy 32, 333-350.

Gilbert, R. J. and D. M. Newbery (1982). Preemptive patenting and the persistence of monopoly. American Economic Review 72, 12514-526. 
Jehiel, P. and B. Moldovanu (1996). Strategic nonparticipation. RAND Journal of Economics 27, 84-98.

Jehiel, P. and B. Moldovanu (2000). Auctions with downstream interaction among buyers. RAND Journal of Economics 31, 768-791.

Jehiel, P., B. Moldovanu, and E. Stacchetti (1996). How (not) to sell nuclear weapons. American Economic Review 86, 814-829.

Katz, M. L. and C. Shapiro (1985). Network externalities, competition and compatibility. American Economic Review 75, 424-440.

Katz, M. L. and C. Shapiro (1986). How to licence intangible property. Quarterly Journal of Economics 101, 567-590.

Katz, M. L. and C. Shapiro (1992). Product introduction with network externalities. Journal of Industrial Economics 40, 55-83.

Malueg, D. A. and M. Schwartz (2006). Compatibility incentives of a large network facing multiple rivals. Journal of Industrial Economics 54, 527-67.

Norbäck, P.-J. and L. Persson (2009). The organization of the innovation industry: Entrepreneurs, venture capitalists, and oligopolists. Journal of the European Economic Association 7, 1261-1290.

Norbäck, P.-J. and L. Persson (2012). Entrepreneurial innovations, competition and competition policy. European Economic Review 56, 488-506.

Norbäck, P.-J., L. Persson, and R. Svensson (2011). Creative destruction and productive preemption. CEPR Discussion Paper No. DP8281.

Norbäck, P.-J., L. Persson, and J. Tåg (2010). Buying to sell: Private equity buyouts and industrial restructuring. IFN Working Paper No. 817. Available at SSRN: http://ssrn.com/abstract $=1532757$.

Salant, S. W., S. Switzer, and R. J. Reynolds (1983). Losses from horizontal merger: The effects of an exogeneous change in industry structure on Cournot-Nash equilibrium. Quarterly Journal of Economics 98, 185-199, 185-199. 


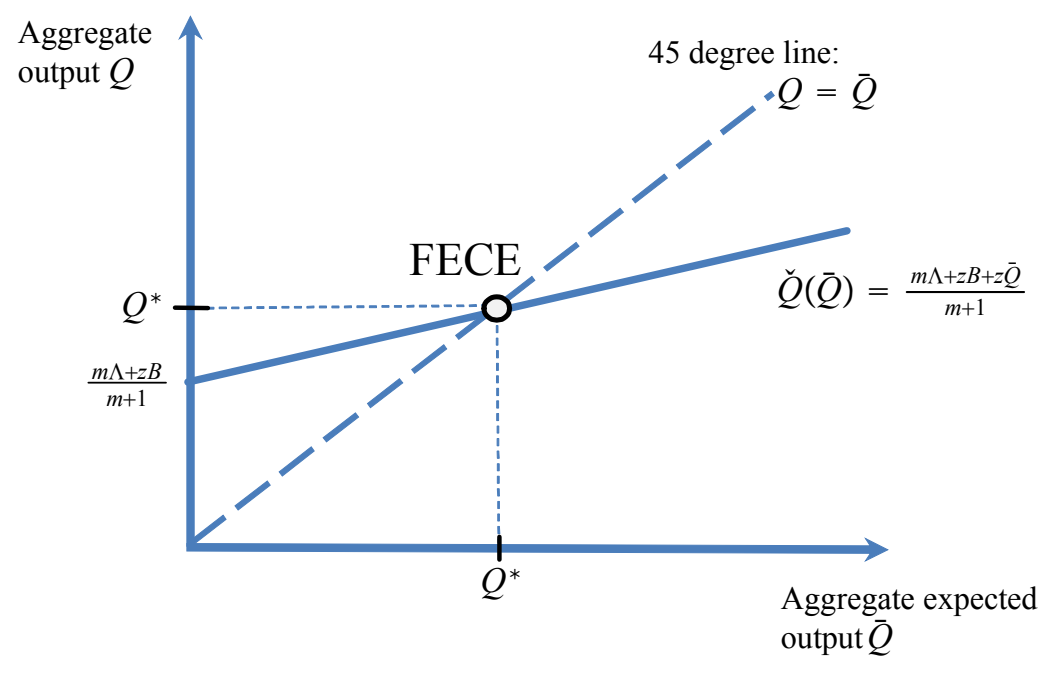

Figure 4: Illustrating the Fulfilled Expectations Cournot Equilibrium (FECE).

\section{A Appendix}

\section{A.1 Existence of a fulfilled expectations equilibrium}

To see this, substitute (1) into (3) and sum over all $m$ firms. Solve for total output $Q^{*}=\sum_{j}^{m} q_{j}^{*}$ as a function of total expected output $\bar{Q}=\sum_{j}^{m} \bar{q}_{j}$. Denote this solution

$$
\check{Q}(\bar{Q})=\frac{m \Lambda+z B+z \bar{Q}}{m+1},
$$

where $\Lambda=T-c$, and $B=\sum_{j}^{m} b_{j}$ is the aggregate installed base. In Figure 4 , we depict the locus of $\check{Q}(\bar{Q})$. The figure also plots the 45 degree line where firms' aggregate output is equal to expected aggregate output, $Q=\bar{Q}$. It follows that the locus $\check{Q}(\bar{Q})$ only intersects the 45 degree line once since $\check{Q}(0)>0$ and $d \check{Q} / d \bar{Q}=z /(m+1)<$ 1. Hence, there exists a unique Fulfilled Expectations Cournot Equilibrium (FECE), $Q^{*}=\sum_{j}^{m} q_{j}^{*}=\bar{Q}$. Furthermore, the Fulfilled Expectations Cournot Equilibrium is stable. To see this, note that an increase in firms' aggregate output $\check{Q}(\bar{Q})$, from say an increase in the aggregate installed base $B$, shifts the locus of $\check{Q}(\bar{Q})$ upwards for any positive expectation by consumers $\bar{Q}$. This increase in aggregate output by firms is then accompanied by an increase in expected aggregate output by consumers, $\bar{Q}$. 


\section{A.2 Firm profits and network effects}

To examine in more detail how network effects affect profits, use the reduced-form profit function $\pi_{j}^{*}$ to obtain

$$
\begin{aligned}
\frac{d \pi_{j}^{*}}{d z} & =\frac{\partial \pi_{j}}{\partial z}+\frac{\partial \pi_{j}}{\partial q_{j}} \frac{d q_{j}^{*}}{d z}+\frac{\partial \pi_{j}}{\partial q_{-j} \frac{d q_{-j}^{*}}{d z}} \\
& =[\underbrace{q_{j}^{*}+b_{j}}_{\text {Direct price effect }}+\underbrace{z \frac{\partial q_{j}^{*}}{\partial z}}_{\text {Network effect }}-\underbrace{\frac{d q_{-j}^{*}}{d z}}_{\text {Strategic effect }}] q_{j}^{*} .
\end{aligned}
$$

The first term on the first line represents the direct effect on profits from a change in $z$. The second term on the first line represents the indirect effect of $z$ on profits through own output. It is zero by the envelope theorem. The final term on the first line represents the strategic effect of $z$ on profits through the effect of rivals output. Applying fulfilled consumer expectations $\bar{q}_{j}=q_{j}^{*}$, we then obtain the second line. From (1), the first terms within the bracket on the last line represent a direct price effect: for a given network size, stronger network effects increase the consumers' willingness to pay. The second term is a direct network effect which arises as consumers' willingness to pay also changes from a changing expected network size. The sign of the direct network effect is ambiguous. It will depend on whether consumers expect that the firm's network will expand or contract. The last term within the bracket represents the strategic price effect arising from the change in price generated by the induced change in the output of competitors. The sign of this effect is also ambiguous - it will depend on the outcome in the interaction on the product market.

\section{A.3 Proof of Lemma 1}

We start with demonstrating how to obtain equation the expression for how network effects affect the profits of firm $j$. From (4) and (5), we have

$$
\begin{aligned}
\frac{d q_{j}^{*}}{d z} & =\frac{\Lambda+z b_{j}-Q^{*}}{(1-z)^{2}}+\frac{b_{j}}{1-z}-\frac{\frac{d Q^{*}}{d z}}{1-z} \\
& =\left(\frac{1}{1-z}\right)\left(q_{j}^{*}+b_{j}-\frac{d Q^{*}}{d z}\right)
\end{aligned}
$$


with

$$
\begin{aligned}
\frac{d Q^{*}}{d z} & =\frac{B}{m+1-z}+\frac{m \Lambda+z B}{(m+1-z)^{2}} \\
& =\frac{B}{m+1-z}+\frac{Q^{*}}{m+1-z} .
\end{aligned}
$$

Since the reduced profit function is quadratic in output, we have

$$
\frac{d \pi_{j}^{*}}{d z}=2 \frac{d q_{j}^{*}}{d z} q_{j}^{*}
$$

Using equations (16) and (17) in (18), we have

$$
\begin{aligned}
\frac{d \pi_{j}^{*}}{d z} & =2\left(\frac{1}{1-z}\right)\left(q_{j}^{*}+b_{j}-\frac{d Q^{*}}{d z}\right) q_{j}^{*} \\
& =2\left(\frac{1}{1-z}\right)\left(q_{j}^{*}+b_{j}-\left(\frac{B}{m+1-z}+\frac{Q^{*}}{m+1-z}\right)\right) q_{j}^{*} \\
& =2\left(\frac{Q^{*}+B}{1-z}\right)\left(\varphi_{j}^{*}-\frac{1}{m}+\frac{1-z}{m[m+1-z]}\right) q_{j}^{*} .
\end{aligned}
$$

where simplifying (19) gives (6). To show the properties of the profit functions below, we make use of the quadratic profits, $\frac{d \pi_{j}^{*}}{d z}=2 \frac{d q_{j}^{*}}{d z} q_{j}^{*}$. Since $q_{j}^{*}>0$, it follows that

$$
\operatorname{sign}\left[\frac{d \pi_{j}^{*}}{d z}\right]=\operatorname{sign}\left[\frac{d q_{j}^{*}}{d z}\right] \text {. }
$$

\section{A.3.1 (i) No innovation is discovered: Profit of incumbents: $\pi_{N}^{*}$}

As the relative network size is $\varphi_{j}^{*}=\frac{1}{m}$, with $m=n$, it follows directly from 6 that incumbent profits $\pi_{N}^{*}$ are strictly increasing in $z$.

\section{A.3.2 (ii) Acquisition: Profit of the acquirer: $\pi_{A}^{*}$}

Let us start with the acquirer's profits, $\pi_{A}^{*}$, noting that $m=n$. To simplify the notation, write $\frac{d q_{A}^{*}}{d z}=q_{A, z}^{*}$. Solve for $k$ as a function of $z$ such that $q_{A, z}^{*}=0$ and denote this $\left.k(z)\right|_{q_{A, z}^{*}=0}$. Then, by calculation

$$
\left.k(z)\right|_{q_{A, z}^{*}=0}=-\frac{(1-z)^{2}(b+\Lambda+b n)}{n-2 z-2 n z+n^{2}+2 z^{2}}<0 .
$$


Note that (20) imply that $q_{A, z}^{*}>0$ for $z=0$. Then, since $k \in[0, b), q_{A, z}^{*}>0$ for $z \in[0,1)$. Hence, from (20) we must have $\frac{d \pi_{A}^{*}}{d z}>0$ for $z \in[0,1)$. Thus, the acquiring incumbent's reduced-form product market profit $\pi_{A}^{*}$ is strictly increasing in network effects, $z$.

\section{A.3.3 (iii) Acquisition: Profit of a non-acquirer: $\pi_{N A}^{*}$}

Then, turn to the profit of a non-acquirer, $\pi_{N A}^{*}$, again noting that $m=n$. This is illustrated in Figure 5(i). Solving $\left.k(z)\right|_{q_{N A, z}^{*}=0}$, we obtain:

$$
\left.k(z)\right|_{q_{N A, z}^{*}=0}=(1-z)^{2} \frac{b+\Lambda+b n}{n+1-z^{2}} \geq 0 .
$$

Note that $\left.k^{\prime}(z)\right|_{q_{N A, z}^{*}=0}=-2(1-z)(n-z+1) \frac{b+\Lambda+b n}{\left(n-z^{2}+1\right)^{2}}<0$. Furthermore, note that we have $\left.k(0)\right|_{q_{N A, z}^{*}=0}=b+\frac{\Lambda}{n+1}$ and that $\lim _{z \rightarrow 1}\left[\left.k(z)\right|_{q_{N A, z}^{*}=0}\right]=0$. Thus, as shown in Figure 5(i), for any $k \in(0, b)$, there will exist a unique $z_{N A}=\left.k^{-1}(z)\right|_{q_{N A, z}^{*}=0} \in(0,1)$ such that $q_{N A, z}^{*}>0$ for $z \in\left[0, z_{N A}\right), q_{N A, z}^{*}=0$ for $z=z_{N A}$ and $q_{N A, z}^{*}<0$ for $z \in\left(z_{N A}, 1\right)$. Once more, from $(20)$, it then follows that $\pi_{N A}^{*}$ is strictly concave in the network effect, $z$, with a unique maximum $z_{N A} \in(0,1)$.

In Figure 5(i), we also illustrate the line $\left.k(z)\right|_{q_{N A}^{*}=0}$, that is, the combination of $k$ and $z$ at which tipping occurs and where only the acquiring incumbent becomes a monopolist. By calculation:

$$
\left.k(z)\right|_{q_{N A}^{*}=0}=(1-z) \frac{\Lambda+b z}{z},
$$

where $\left.k(z)\right|_{q_{N A}^{*}=0}=-\frac{\Lambda+b z^{2}}{z^{2}}<0, \lim _{z \rightarrow 0}\left[\left.k(z)\right|_{q_{N A}^{*}=0}\right]=\infty$ and $\lim _{z \rightarrow 1}\left[\left.k(z)\right|_{q_{N A}^{*}=0}\right]=$ 0 . Then, tipping to the acquiring incumbent occurs for $z>z_{N A}^{\max }=\left.k^{-1}(z)\right|_{q_{N A}^{*}=0}$. Thus, to the right of the locus $\left.k(z)\right|_{q_{N A}^{*}=0}$ in Figure 5(i), the non-acquiring incumbents will exit where

$$
\left.k(z)\right|_{q_{N A, z}^{*}=0}-\left.k(z)\right|_{q_{N A}^{*}=0}=-(1-z)\left(\Lambda+b z^{2}\right) \frac{n-z+1}{z\left(n-z^{2}+1\right)}<0 .
$$




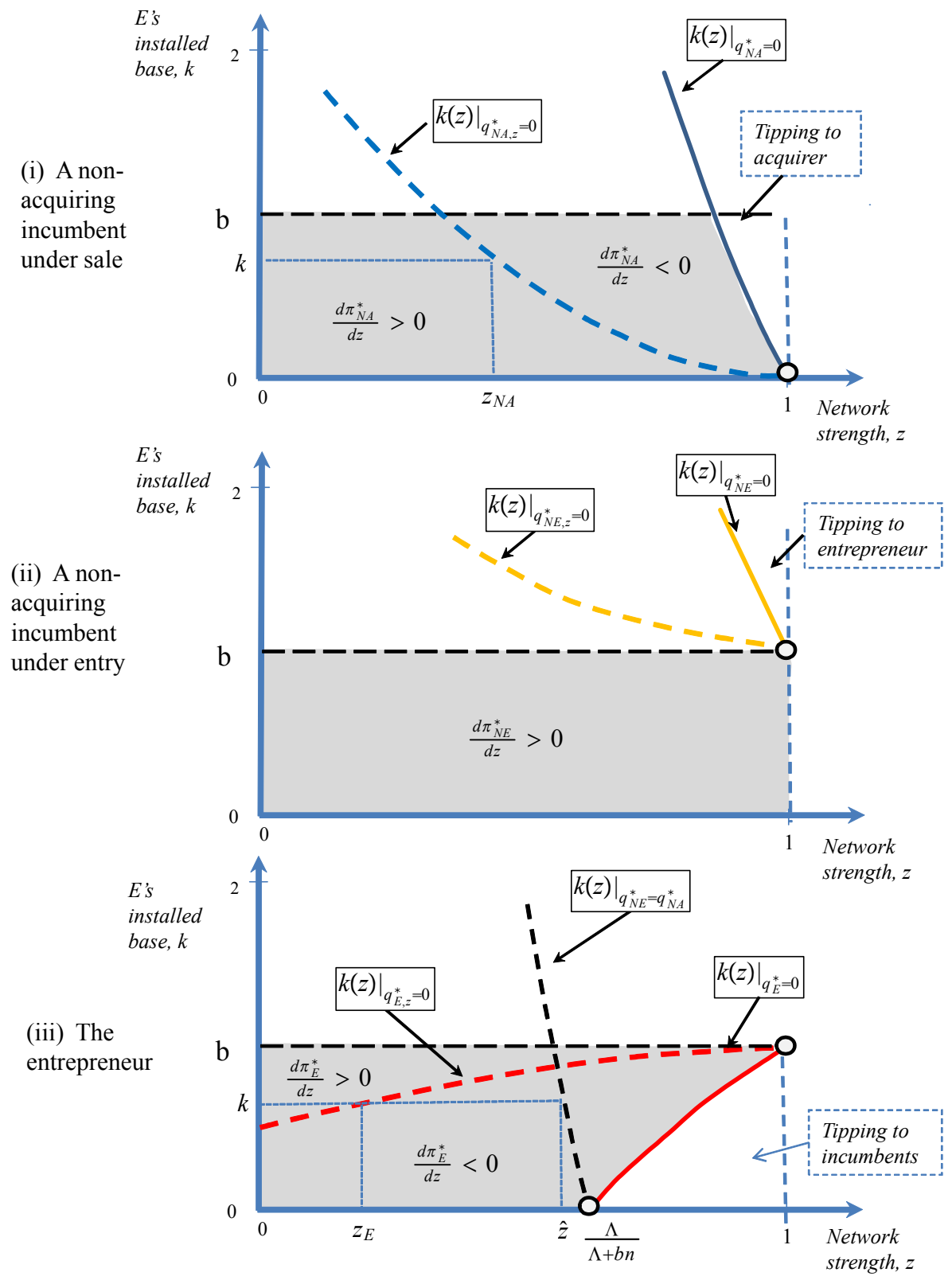

Figure 5: Illustrating the properties of $\pi_{h}^{*}$. Parameter values set to $n=3, b=1$, and $\Lambda=T-c=5$. 


\section{A.3.4 (vi) Entry: Profit of the entrant: $\pi_{E}^{*}$}

Now, turn to the profit of the entrepreneur, $\pi_{E}$. Noting that $m=n+1$ and solving $\left.k(z)\right|_{q_{E, z}^{*}=0}$, we obtain:

$$
\left.k(z)\right|_{q_{E, z}^{*}=0}=\frac{-\Lambda+2 z \Lambda+b n^{2}-z^{2} \Lambda+2 b n-b n z^{2}}{3 n-4 z-2 n z+n^{2}+2 z^{2}+2} .
$$

By calculation, we have $\left.k^{\prime}(z)\right|_{q_{E, z}^{*}=0}=2 n \frac{(1-z)(2 b+\Lambda+b n)(n-z+2)}{\left(3 n-4 z-2 n z+n^{2}+2 z^{2}+2\right)^{2}}>0$, and $\left.k(0)\right|_{q_{E, z}^{*}=0}=$ $\frac{-\Lambda+b n(n+2)}{(n+2)(n+1)}$. Note also that finally, $\lim _{z \rightarrow 1}\left[\left.k(z)\right|_{q_{E, z}^{*}=0}\right]=b$. There will then exist a unique $z_{E}=\left.k^{-1}(z)\right|_{q_{E, z}^{*}=0} \in(0,1)$ such that $q_{E, z}^{*}>0$ for $z \in\left[0, z_{E}\right), q_{E, z}^{*}=0$ for $z=z_{E}$ and $q_{E, z}^{*}<0$ for $z \in\left(z_{E}, 1\right)$. From (20), it then follows that $\pi_{E}^{*}$ is strictly concave in the network effect, $z$, with a unique maximum $z_{E} \in(0,1)$.

In Figure 5(ii), we illustrate the line $\left.k(z)\right|_{q_{E}^{*}=0}$, that is, the combination of $k$ and $z$ at which tipping towards incumbents occurs and where only the incumbent would remain (so the entrepreneur would not enter). By calculation:

$$
\left.k(z)\right|_{q_{E}^{*}=0}=\frac{(z-1) \Lambda+b n z}{z(n-z+1)} .
$$

We then have $\left.k^{\prime}(z)\right|_{q_{E}^{*}=0}=\frac{\Lambda+n \Lambda-2 z \Lambda+z^{2} \Lambda+b n z^{2}}{z^{2}(n-z+1)^{2}}>0, \lim _{z \rightarrow 0}\left[\left.k(z)\right|_{q_{E}^{*}=0}\right]=-\infty$ and also $\lim _{z \rightarrow 1}\left[\left.k(z)\right|_{q_{E}^{*}=0}\right]=b$.

Then, tipping to incumbents occurs for $z>z_{E}^{\max }=k^{-1}(z)_{q_{E}^{*}=0}$. Note also that $\left.k(z)\right|_{q_{E}^{*}=0}=0$ for $z=\frac{\Lambda}{\Lambda+b n} \in(0,1)$. Thus, to the right of the upward-sloping locus $\left.k(z)\right|_{q_{N E}^{*}=0}$ in Figure 5(iii), the entrepreneur will never enter the market. Note, finally, that

$$
\left.k(z)\right|_{q_{N E, z}^{*}=0}-\left.k(z)\right|_{q_{E}^{*}=0}=\frac{(1-z)(n-z+2)\left(\Lambda+n \Lambda-2 z \Lambda+z^{2} \Lambda+b n z^{2}\right)}{z(n-z+1)\left(3 n-4 z-2 n z+n^{2}+2 z^{2}+2\right)}>0 .
$$

\section{A.3.5 (v) Entry: Profit of a non-acquirer: $\pi_{N E}^{*}$}

Consider the profit of a non-acquirer under entry, $\pi_{N E}^{*}$. This is illustrated in Figure 5(ii). Noting that $m=n+1$ and solving for $\left.k(z)\right|_{q_{N E, z}^{*}=0}$, we obtain:

$$
\left.k(z)\right|_{q_{N E, z}^{*}=0}=\frac{\left(z^{2}-2 z+1\right) \Lambda+b\left(4+z^{2}-4 z+2 n+n z^{2}-2 n z\right)}{n-z^{2}+2}>0
$$

since $n \geq 2$ and $z \in[0,1)$.

Note that $\left.k^{\prime}(z)\right|_{q_{N E, z}^{*}=0}=-2(1-z)(2 b+\Lambda+b n) \frac{n-z+2}{\left(n-z^{2}+2\right)^{2}}<0$, and that $\left.k(0)\right|_{q_{N E, z}^{*}=0}=$ 
$2 b+\frac{\Lambda}{n+2}$ and $\lim _{z \rightarrow 1}\left[\left.k(z)\right|_{q_{N E, z}^{*}=0}\right]=b$. Note also that part (i) of the Lemma implies that $q_{N E, z}^{*}>0$ for $z=0$. Thus, as shown in Figure 5(ii), since $k \in[0, b)$ from Assumption 1 , we must have $q_{N E, z}^{*}>0$ for $z \in[0,1)$. Hence, from $(20), \frac{d \pi_{N E}^{*}}{d z}>0$ for $z \in[0,1)$. Thus, a non-acquiring incumbent's reduced-form product market profit $\pi_{N E}^{*}$ is strictly increasing in network effects, $z$.

In Figure 5(i), we also illustrate the line $\left.k(z)\right|_{q_{N E}^{*}=0}$, that is, the combination of $k$ and $z$ at which tipping occurs and where only the entrepreneur remains. By calculation:

$$
\left.k(z)\right|_{q_{N E}^{*}=0}=\frac{\Lambda-z \Lambda-b z^{2}+2 b z}{z}
$$

where $\left.k^{\prime}(z)\right|_{q_{N E}^{*}=0}=-\frac{\Lambda+b z^{2}}{z^{2}}<0, \lim _{z \rightarrow 0}\left[\left.k(z)\right|_{q_{N E}^{*}=0}\right]=\infty$ and $\lim _{z \rightarrow 1}\left[\left.k(z)\right|_{q_{N E}^{*}=0}\right]=$ $b$. Thus, since $k \in[0, b), q_{N E}^{*}>0$, and hence $\pi_{N E}^{*}>0$. Due to the larger installed base of incumbents, tipping in terms of incumbents being driven out by the entrepreneur can never occur under Assumption 1.

\section{A.3.6 Proof of Corollary 1}

Solving for the combination of $k$ and $z$ at which non-acquirers' profits are the same under entry and sale $\left.k(z)\right|_{q_{N E}^{*}=q_{N A}^{*}}$, we obtain:

$$
\left.k(z)\right|_{q_{N E}^{*}=q_{N A}^{*}}=\frac{\Lambda(1-z)-b n z}{z} .
$$

By calculation, $\left.k^{\prime}(z)\right|_{q_{N E}^{*}=q_{N A}^{*}}=-\frac{\Lambda}{z^{2}}<0$ and $\lim _{z \rightarrow 0}\left[\left.k(z)\right|_{q_{N E}^{*}=q_{N A}^{*}}\right]=\infty$. Note also that $\lim _{z \rightarrow 1}\left[\left.k(z)\right|_{q_{N E}^{*}=q_{N A}^{*}}\right]=-b n<0$. Thus, as shown in Figure 5(iii), there will exist a unique $\hat{z} \in(0,1)$ such that $q_{N E}^{*}<q_{N A}^{*}$ for $z \in[0, \hat{z}), q_{N E}^{*}=q_{N A}^{*}$ for $z=\hat{z}$ and $q_{N E}^{*}>q_{N A}^{*}$ for $z \in\left(\hat{z}_{N}, 1\right)$.

Note finally that $\left.k(z)\right|_{q_{N E}^{*}=q_{N E}^{*}}=0$ for $z=\frac{\Lambda}{\Lambda+b n} \in(0,1)$, that is, we have $\left.k(z)\right|_{q_{N E}^{*}=q_{N E}^{*}}=$ $0=\left.k(z)\right|_{q_{E}^{*}=0}$ for $z=\frac{\Lambda}{\Lambda+b n}$.

\section{A.4 Proof of Lemma 2}

Note that $b_{i} \geq \max v_{i j}, j=\{e, i\}$, is a weakly dominated strategy, since no firm will post a bid equal to or above its maximum valuation of obtaining the entrepreneurial firm. The entrepreneurial firm $e$ will accept a bid iff $b_{i} \geq v_{e}$. 
Inequality I1 Consider equilibrium candidate $\mathbf{b}^{*}=\left(b_{1}^{*}, b_{2}^{*}, \ldots\right.$, yes $)$. Let us assume that incumbent $w$ is the incumbent that has posted the highest bid and obtains the assets, and that firm $\varsigma$ is the incumbent with the second highest bid.

Then, $b_{w}^{*} \geq v_{i i}$ is a weakly dominated strategy. $b_{w}^{*}<v_{i i}-\varepsilon$ is not an equilibrium, since firm $j \neq w, e$ then benefits from deviating to $b_{j}=b_{w}^{*}+\varepsilon$, since it will then obtain the assets and pay a price lower than its valuation of obtaining them. If $b_{w}^{*}=v_{i i}-\varepsilon$, and $b_{\varsigma}^{*} \in\left[v_{i i}-2 \varepsilon, v_{i i}-\varepsilon\right]$, then no incumbent has an incentive to deviate. By deviating to no firm, $e$ loses since $b_{w}^{*}=v_{i i}-\varepsilon>v_{e}$. Accordingly, the entrepreneur has no incentive to deviate and thus, $\mathbf{b}^{*}$ is a Nash equilibrium.

Let $\mathbf{b}=\left(b_{1}, \ldots, b_{n}, n o\right)$ be a Nash equilibrium. Let incumbent $h$ be the incumbent with the highest bid. The entrepreneur will then say no iff $b_{h} \leq v_{e}$. But incumbent $j \neq e$ will have the incentive to deviate to $b^{\prime}=v_{e}+\varepsilon$ in period 1 , since $v_{i e}>v_{e}$. This contradicts the assumption that $\mathbf{b}$ is a Nash equilibrium.

Inequality I2 Consider equilibrium candidate $\mathbf{b}^{*}=\left(b_{1}^{*}, b_{2}^{*}, \ldots\right.$, yes $)$. Let us assume that incumbent $w$ is the incumbent that has posted the highest bid and obtains the assets, and that firm $\varsigma$ is the incumbent with the second highest bid. Then, $b_{w}^{*} \geq v_{i i}$ is a weakly dominated strategy. $b_{w}^{*}<v_{i i}-\varepsilon$ is not an equilibrium since firm $j \neq w, \varsigma, e$ then benefits from deviating to $b_{j}=b_{w}^{*}+\varepsilon$, since it will then obtain the assets and pay a price lower than its valuation of obtaining them. If $b_{w}^{*}=v_{i i}-\varepsilon$, and $b_{\varsigma}^{*} \in\left[v_{i i}-2 \varepsilon, v_{i i}-\varepsilon\right]$, no incumbent has an incentive to deviate. By deviating to no, firm $e$ loses since $b_{w}^{*}=$ $v_{i i}-\varepsilon>v_{e}$. Accordingly, the entrepreneur has no incentive to deviate and thus, $\mathbf{b}^{*}$ is a Nash equilibrium.

Consider the equilibrium candidate $\mathbf{b}^{* *}=\left(b_{1}^{* *}, b_{2}^{* *}, \ldots, n o\right)$. Then, $b_{w}^{*} \geq v_{e}$ is not an equilibrium since the entrepreneur would benefit by deviating to yes. If $b_{w}^{*} \leq v_{e}$, then no incumbent has an incentive to deviate. By deviating to yes, the entrepreneur's payoff decreases since it then sells its assets at a price below its valuation, $v_{e}$. The entrepreneur has no incentive to deviate and thus, $\mathbf{b}^{* *}$ is a Nash equilibrium.

Inequality I3 Consider equilibrium candidate $\mathbf{b}^{*}=\left(b_{1}^{*}, b_{2}^{*}, \ldots\right.$, yes $)$. Let us assume that incumbent $w$ is the incumbent that has posted the highest bid and obtains the assets, and that firm $\varsigma$ is the incumbent with the second highest bid. Then, $b_{w}^{*} \geq v_{i i}$ is not an equilibrium since firm $w$ would then benefit from deviating. $b_{w}^{*}<v_{i i}-\varepsilon$ is not an equilibrium since firm $j \neq w$ then benefits from deviating to $b_{j}=b_{w}^{*}+\varepsilon$, since it will then obtain the assets and pay a price lower than its valuation of obtaining them. If $b_{w}^{*}=v_{i i}-\varepsilon$, and $b_{\varsigma}^{*} \in\left[v_{i i}-2 \varepsilon, v_{i i}-\varepsilon\right]$, no incumbent has an incentive to deviate. By 
deviating to $n o$, firm $e$ loses since $b_{w}^{*}=v_{i i}-\varepsilon>v_{e}$. Accordingly, the entrepreneur has no incentive to deviate and thus, $\mathbf{b}^{*}$ is a Nash equilibrium.

Let $b=\left(b_{1}, \ldots, b_{n}, n o\right)$ be a Nash equilibrium. The entrepreneur will then say no iff $b_{h}<v_{e}$. But incumbent $j \neq e$ will then have the incentive to deviate to $b^{\prime}=v_{e}+\varepsilon$ in Stage 1 , since $v_{i e}>v_{e}$. This contradicts the assumption that $\mathbf{b}$ is a Nash equilibrium.

Inequality I4 Consider equilibrium candidate $b^{*}=\left(b_{1}^{*}, b_{2}^{*}, \ldots\right.$, yes $)$. Then, $b_{w}^{*}>v_{e}$ is not an equilibrium since firm $w$ would then benefit from deviating to $b_{w}=v_{e}$. $b_{w}^{*}<v_{e}$ is not an equilibrium, since the entrepreneur would then not accept any bid. If $b_{w}^{*}=v_{e}-\varepsilon$, then firm $w$ has no incentive to deviate. By deviating to $b_{j}^{\prime} \leq b_{w}^{*}$, firm $j$ 's, $j \neq w, e$, payoff does not change. By deviating to $b_{j}^{\prime}>b_{w}^{*}$, firm $j$ 's payoff decreases since it must pay a price above its willingness to pay, $v_{i i}$. Accordingly, firm $j$ has no incentive to deviate. By deviating to no, the entrepreneur's payoff decreases since it foregoes a selling price above its valuation $v_{e}$. Accordingly, the entrepreneur has no incentive to deviate and thus, $b^{*}$ is a Nash equilibrium.

Let $b=\left(b_{1}, \ldots, b_{n}, n o\right)$ be a Nash equilibrium. The entrepreneur will then say no iff $b_{h}<v_{e}$. But incumbent $j$ will have the incentive to deviate to $b^{\prime}=v_{e}+\varepsilon$ in Stage 1 since $v_{i e}>v_{e}$, which contradicts the assumption that $b$ is a Nash equilibrium.

Inequalities I5 or I6 Consider equilibrium candidate $b^{*}=\left(b_{1}^{*}, b_{2}^{*}, \ldots, n o\right)$, where $b_{j}^{*}<$ $v_{e} \forall j$. It then directly follows that no firm has an incentive to deviate and thus, $b^{*}$ is a Nash equilibrium.

Then, note that the entrepreneur will accept a bid iff $b_{j} \geq v_{e}$. But $b_{j} \geq v_{e}$ is a weakly dominating bid in these intervals, since $v_{e}>\max \left\{v_{i i}, v_{i e}\right\}$. Thus, the assets will not be sold in these intervals.

\section{A.5 Proof of Proposition 1}

We first examine $v_{i i}(z)$. Note that $v_{i i, z}^{\prime}(0)=2 k \frac{\Lambda}{n+1}>0$. Then, solve for the combination of $k$ and $z$ at which the derivative of the preemptive valuation in $z$ is zero, $\left.k(z)\right|_{v_{i i, z}=0}$. We obtain

$$
\left.k(z)\right|_{v_{i i, z}^{\prime}=0}=(z-1) \frac{\left(n-z^{2}+1\right) \Lambda+b z(2-2 z+2 n-n z)}{z\left(-z-2 n z+n^{2}+2 z^{2}-1\right)}<0 .
$$

But then $n \geq 2$ and since $k \in[0, b)$ from Assumption 1, we must have $v_{i i, z}^{\prime}>0$ for $z \in[0,1)$. Thus, the acquiring incumbent's preemptive valuation $v_{i i}$ is strictly increasing in network effects. 
To proceed, we find that

$$
v_{i e}(0)=\frac{(2 n+3) \Lambda^{2}}{(n+2)^{2}(n+1)^{2}}>0=v_{i i}(0)
$$

and that

$$
v_{e}(0)-v_{i e}(0)=\Lambda^{2} \frac{n^{2}-2}{(n+2)^{2}(n+1)^{2}}>0 .
$$

Thus, we have shown that $v_{e}>v_{i e}>v_{i i}$ at $z=0$. From Table 1 and inequality I6, there is entry in equilibrium when the network effects are sufficiently weak. Thus, we have proven part (i) of the proposition.

From Lemma $1, v_{e}=\pi_{E}$ is strictly concave in network effects, $z$, with a unique maximum $z_{E} \in(0,1)$. But since $v_{i i}$ is strictly increasing in network effects, $z, v_{i i}>v_{e}$ must hold when $z$ becomes sufficiently large, i.e. when it approaches $z_{E}=\left.k^{-1}(z)\right|_{q_{E, z}^{*}=0}$.

Moreover, note that if we evaluate $v_{i e}$ at $\left.k(z)\right|_{q_{E}^{*}=0}$, we obtain

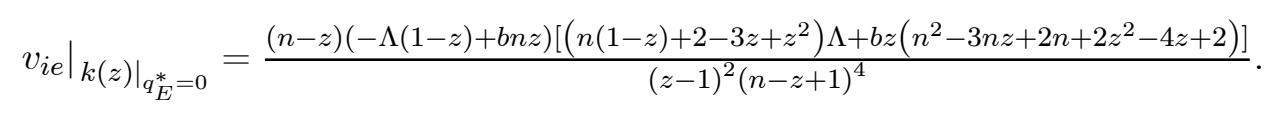

To evaluate (34), first note that $-\Lambda(1-z)+b n z>0$, if $z>\frac{\Lambda}{\Lambda+b n}$. Then note that

$$
\left(n(1-z)+2-3 z+z^{2}\right) \Lambda+b z\left(n^{2}-3 n z+2 n+2 z^{2}-4 z+2\right)>0
$$

since $z \in[0,1)$ and $n \geq 2$. To proceed, note that (26) implies that for any $k \in(0, b)$, we must have $z_{E}^{\max }=\left.k^{-1}(z)\right|_{q_{E}^{*}=0}>\frac{\Lambda}{\Lambda+b n}$. Corollary 1, (7) and (8) then imply that for $z \in\left(z_{N}, 1\right), v_{i i}(z)>v_{i e}(z)$. From (30), we have that $\left.k\left(\frac{\Lambda}{\Lambda+b n}\right)\right|_{q_{N E}^{*}=q_{N A}^{*}}=0$. Since $\left.k^{\prime}(z)\right|_{q_{N E}^{*}=q_{N A}^{*}}<0$, it now follows that $v_{i i}>v_{i e}$ holds at $\left.k(z)\right|_{q_{E}^{*}=0}$ for $k>0$. This can be seen in Figure 5(iii) where the locus of $\left.k(z)\right|_{q_{N E}^{*}=q_{N A}^{*}}=0$ is always to the left of the locus $\left.k(z)\right|_{q_{E}^{*}}=0$ if $k \in(0, b)$. Thus, we have shown that inequality $v_{i i}>v_{i e}>v_{e}=0$ holds at $\left.k(z)\right|_{q_{E}^{*}=0}$. From Table 1, this implies that inequality I1 holds and the innovation is sold at bidding competition, $l^{*}=i$ and $S^{*}=v_{i i}$ when the network effects become sufficiently strong. Thus, we have proven part (ii) of the proposition.

\section{A.6 Proof of Proposition 5}

By calculation,

$$
v_{i i, b}^{\prime}=2 k \frac{z^{2}}{(1-z)(n-z+1)}>0
$$


and

$$
v_{e, b}^{\prime}=-2 n z \frac{\Lambda-z \Lambda-k z^{2}+k z-b n z+k n z}{(z-1)^{2}(n-z+2)^{2}}<0
$$

since $n \geq 2$ and $z \in[0,1)$. 